Journal of Advanced Research in Fluid Mechanics and Thermal Sciences

\title{
Assessment on Energy Conversion Efficiency and GHG Emissions Rate for Coal, Natural Gas and Biomass Power Plant in Malaysia
}

\author{
Radin Diana R. Ahmad ${ }^{1,3,}{ }^{*}$, Tiong Sieh Kiong ${ }^{2}$, Sazalina Zakaria ${ }^{1}$, Ahmad Rosly Abbas ${ }^{1}$, Chen Chai \\ Phing ${ }^{2}$, Kamil Abdullah ${ }^{3}$

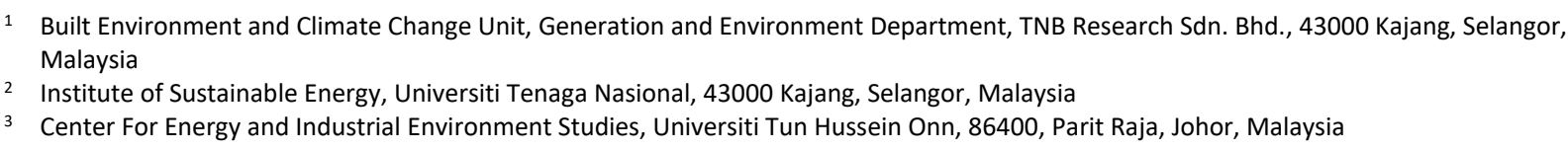

\section{Article history:}

Received 29 May 2021

Received in revised form 15 August 2021

Accepted 20 August 2021

Available online 27 September 2021

\section{Keywords:}

Energy conversion efficiency; GHGs; coal power plant; natural gas power plant; biomass power plant

\begin{abstract}
Three different power plants have been assessed in terms of energy conversion efficiency and GHGs emission rate. The power plants are coal power plant, natural gas power plant and biomass power plant. The assessments are made by collecting fuels consumption data and generated electricity data of each power plant. In addition to the data collection, observation on operational practices have also been carried out. The energy conversion efficiency and the GHGs emission rate for all power plants are recorded to be lower than the typical values proposed by the literature. The biomass power plant recorded the lowest energy conversion efficiency at $6.47 \%$. Meanwhile, the natural gas power plant utilizing the combined cycle gas turbine technology recorded the highest overall energy conversion efficiency at $48.35 \%$ and rated to emit GHGs at $0.32 \mathrm{~kg} \mathrm{CO}{ }_{2}$ e per kWh.
\end{abstract}

\section{Introduction}

The increasing demand for electricity in the modern world is now inevitable. The progress achieved by a country can now be measured by the energy demand of the country. In a global scale, there has been growing concern over the method of 'low carbon and green growth' which a question on the possibility of achieving sustained economic growth without increasing energy consumption or greenhouse gases has become an interesting topic [1-4]. While the world is now engaging in renewable energy as an alternative to fossil-based energy, the cost of renewable energy-related technologies is still too high [5-7], especially for developing countries. This has led to a developing of country like Malaysia as an example still dependent on fossil-based energy in its electricity-generating sector.

Based on statistics released by the Energy Commission of Malaysia, a total of $85.7 \%$ of the electricity produced in Malaysia for the year 2016 is derived from fossil-based sources (coal \& natural

\footnotetext{
* Corresponding author.

E-mail address: diana.ahmad@tnb.com.my

https://doi.org/10.37934/arfmts.87.2.145153
} 
gas) [8]. The Malaysia's 2007 level of GHG emissions intensity (as a ratio against country's GDP) are above the global average in the energy sector. [9] The use of fossil-based fuels is a major contributor to greenhouse gas emissions that contributes to the global phenomena of climate change [10-13]. The primary greenhouse gases in the Earth's atmosphere are water vapour, carbon dioxide, methane, nitrous oxide, and ozone. Greenhouse gases greatly affect the temperature of the Earth [14]. Hence, measurement of the exclusive total amount of GHG emissions that are directly and indirectly caused by an activity or is accumulated over the life stages of a product [15] is ultimately required to ensure the sustainability of living creatures on earth.

According to records, there is a total of 7 coal-fired power stations and 19 gas stations in Peninsular Malaysia with installed capacities totalling 21,390 GW [16]. In order to realize the Malaysian government's desire to achieve greenhouse gas emissions intensity reduction targets by 45\% in 2030 per GDP [17], systematic efforts need to be made. An energy scenario modeling for Malaysia using LEAP was conducted in order to develop long-range and sustainable power sector scenarios for Malaysia and to build emission and policy scenarios. In the model, four main scenarios have been developed include one reference scenario (BAU) and other three alternative scenarios (MRES, 50-50 Scenario and OES). Through this modelling, the GHG emissions shows reduction due to the implementations of renewable energy along with energies efficiency and the prolong of fossil fuels reserves is achievable. [18]

One of the key activities in the effort to reduce the emission of greenhouse gases is to assess and measure greenhouse gas emissions from existing energy conversion systems. This activity will help in identifying the steps that need to be taken in the future in reducing emissions of greenhouse gases. For this purpose, this paper aims to assess and measure the efficiency of different energy conversion systems and greenhouse gas emissions. The findings of the present paper will provide insight into the present status of Malaysia energy conversion technology and its impacts on the global warming issue.

\section{Methodology}

\subsection{Power Plant}

Three power plants have been considered in the present study representing the coal, natural gas and biomass energy conversion technologies. Table 1 shows details on the considered power plant. Both the coal and natural gas power plants have been designed to serve the baseload demand to the national grid while the biomass power plant is designed to serve during the peak load period. The coal power plant makes use of pulverized coal firing technology while the natural gas power plant utilized the combined cycle gas turbine technology with both power plants have been commissioned in the year 2003 and 2005 respectively. On the other hand, the considered biomass power plant in the present study makes use of biomass fuel technology and has only been commissioned in the year 2014. From all three power plants, only the biomass power plant makes use of the generated electricity for its own consumption (2.5 MW from a total of $12.5 \mathrm{MW}$ ).

Table 1 also provides details on the generation unit configuration for each power plant. The coal power plant is equipped with two units of steam turbine rated at $690 \mathrm{MW}$ each. The unit is powered by steam generated through the burning of the pulverized coal before converting the heat energy of the steam to the electrical energy. The natural gas power plant is equipped with two units of gas turbine rated at $235 \mathrm{MW}$ each and one unit steam turbine rated at $244 \mathrm{MW}$. The gas turbine units will act as primary in producing the electricity and the steam turbine will make use of the steam generated from the heat recovery system; utilizing high pressure and temperature of the gas turbine's exhaust gas. The biomass power plant is equipped with single steam turbine units rated at 
12.5 MW. The power plant makes use of empty fruit branch (EFB) as their fuel to generate steam before converting it to electrical energy via the steam turbine.

Table 1

Details on the power plants

\begin{tabular}{llll}
\hline & Power Plant & & \\
\cline { 2 - 4 } & Coal & Natural Gas & Biomass \\
\hline $\begin{array}{l}\text { Served Load } \\
\text { Technology }\end{array}$ & $\begin{array}{l}\text { Baseload } \\
\text { Pulverized Coal Firing }\end{array}$ & $\begin{array}{l}\text { Baseload } \\
\text { Combine Cycle Gas } \\
\text { Turbine }\end{array}$ & $\begin{array}{l}\text { Peak-load } \\
\text { Biomass Fuel Boiler }\end{array}$ \\
$\begin{array}{lll}\text { Commissioning Year } \\
\text { Fuel Type }\end{array}$ & 2003 & 2005 & 2014 \\
Installed Capacity & Pulverized Coal & Natural Gas & Empty Fruit Branch (EFB) \\
& 715 MW each unit & 703 MW of Unit 1 & 12.5 MW \\
Unit Configuration & (full capacity to grid) & (full capacity to grid) & (10 MW to grid) \\
& ST-A (690 MW) & GT-A (235 MW) & ST (12.5 MW) \\
& ST-B (690 MW) & GT-B (235 MW) & \\
\hline
\end{tabular}

\subsection{Energy Conversion Efficiency}

One of the aims of the present study is to assess the energy conversion efficiency of present different energy conversion system involving coal, natural gas and biomass conversion system. The energy conversion efficiency, $\eta$ generally defined as how well an energy conversion system converting the fuel to produce useful energy, which in the case of the present study representing the electrical energy. Eq. (1) shows the formulation for the energy conversion system efficiency, $\eta$.

$\eta=\frac{\text { Useful Energy Produced }[\mathrm{kWh}]}{\text { Input Energy }[\mathrm{kWh}]} \times 100 \%$

The useful energy is referring to the produced electrical energy by the power plant while the input energy us referring to the amount of heat energy supplied to the power plant through the combustion of its respective fuels.

\subsection{Greenhouse Gas Emission}

Another aim of the present study is to evaluate the greenhouse gas (GHG) emission of the considered energy conversion system. For the purpose of the study, three GHG have been considered, namely carbon dioxide $\left(\mathrm{CO}_{2}\right)$, Methane $\left(\mathrm{CH}_{4}\right)$ and Nitrous Oxide $\left(\mathrm{N}_{2} \mathrm{O}\right)$. The amount of GHG emission released by the energy conversion system can be given by Eq. (2) with EF is the emission factor with respect to fuel for each GHG species [17] and GWP representing the global warming potential of the GHG species. The final value of GHG emission is given in tonne carbon dioxide equivalent $\left(\mathrm{tCO}_{2} \mathrm{e}\right)$.

GHG Emission $\left[\mathrm{tCO}_{2} \mathrm{e}\right]=$ Energy Consumption $[\mathrm{GJ}] \times \mathrm{EF}\left[\frac{\mathrm{kg}}{\mathrm{TJ}}\right] \times \mathrm{GWP}$

Table 2 tabulates the considered values of EF and GWP utilized in the present study. The $\mathrm{EF} \mathrm{CO}_{2}$ for biomass fuel has been registered as $0[\mathrm{~kg} / \mathrm{TJ}]$ due to its unique characteristics which categorized as carbon-neutral fuel [19]. To enable comparison between different energy conversion 
technologies, the derive GHG emission in a kilogram of carbon dioxide equivalent, $\mathrm{kgCO}_{2} \mathrm{e}$ is normalized to the generated electricity, kWh of the respective units as shown in Eq. (3).

GHG Emission Rate $\left[\frac{\mathrm{kgCO}_{2} \mathrm{e}}{\mathrm{kWh}}\right]=\frac{\mathrm{GHG} \text { Emission }\left[\mathrm{tCO}_{2} \mathrm{e}\right]}{\text { Generated Electricity }[\mathrm{kWh}]} \times \frac{1}{100}$

Table 2

Details on emission factors of GHG species and GWP

\begin{tabular}{llllll}
\hline $\begin{array}{l}\text { Greenhouse Gas (GHG) } \\
\text { Species }\end{array}$ & \multicolumn{2}{l}{ Emission Factor, EF [kg/TJ] } & Global Warming \\
\cline { 2 - 5 } & \multicolumn{2}{l}{ Coal } & Natural & Biomass & Potential (GWP) \\
\cline { 2 - 3 } & Sub-Bituminous & Bituminous & Gas & & \\
\hline Carbon dioxide, $\mathrm{CO}_{2}$ & 96.1 & 94.1 & 56.1 & 0 & 1 \\
Methane, $\mathrm{CH}_{4}$ & 0.007 & 0.007 & 0.001 & 30 & 25 \\
Nitrous Oxide, $\mathrm{N}_{2} \mathrm{O}$ & 0.0014 & 0.0014 & 0.003 & 4 & 298 \\
\hline
\end{tabular}

\subsection{Data Collection}

Three different energy conversion technology has been considered in the present study; coal power plant, combined-cycle natural gas power plant and biomass power plant. All three power plants have been managed by different operating companies thus have different data monitoring approach. For the purpose of the study, the main required data are the total fuel consumption and total electricity that has been supplied to the grid for each power plant. Table 3 shows details on data collection involves in the present study. The largest data interval has been made available is for the biomass power plant on a monthly basis. For uniformity purpose, all of the data (coal and natural gas power plants) will be presented in the same monthly interval in the writing. Data for gas and coal power plants have been collected for the period of one year while the data for biomass has only been collected for nine months.

Table 3

Details on data collection interval

\begin{tabular}{llll}
\hline & Power Plant & & \\
\hline Collected Data & Gas & Coal & Biomass \\
Fuel Consumption & Hourly & Daily & Monthly \\
Electricity Generation & Half-hourly & Half-hourly & Monthly \\
\hline
\end{tabular}

\section{Results}

\subsection{Energy Conversion Efficiency}

Figure 1 illustrates the energy conversion efficiency of a coal-fired power plant involving two units of the steam turbines. The power plant utilizing coal in its sub-critical boilers and equipped with pulverized coal technology. Both units (ST-A and ST-B) have recorded energy conversion efficiencies of $35.20 \%$ and $38.77 \%$, respectively. The figure also indicates the standard deviation recorded for both units are at $3.89 \%$ and $3.10 \%$ respectively. In comparison with the recommended energy conversion efficiency for the coal-fired steam turbine (Coal-Fired ST) reported by EURELECTRIC [20] at $39.00 \%$, both of the units are operating at a considerably good level taking into account the plant age which already at 16 years old. Based on the observation during the data collection, the good operational condition of these two units is mainly contributed by the implementation of a systematic maintenance program. This includes proactive and reactive monitoring with leading and lagging 
indicators through the plant operation. Additionally, the observation also shows that good energy efficiency activities have also been conducted by the plant including performance tracking and energy efficiency forum. The performance tracking activity involves monitoring of each station performance during the plant operational period while the energy efficiency forum activities allow idea exchange between the workers to improve the overall performance of the plant.

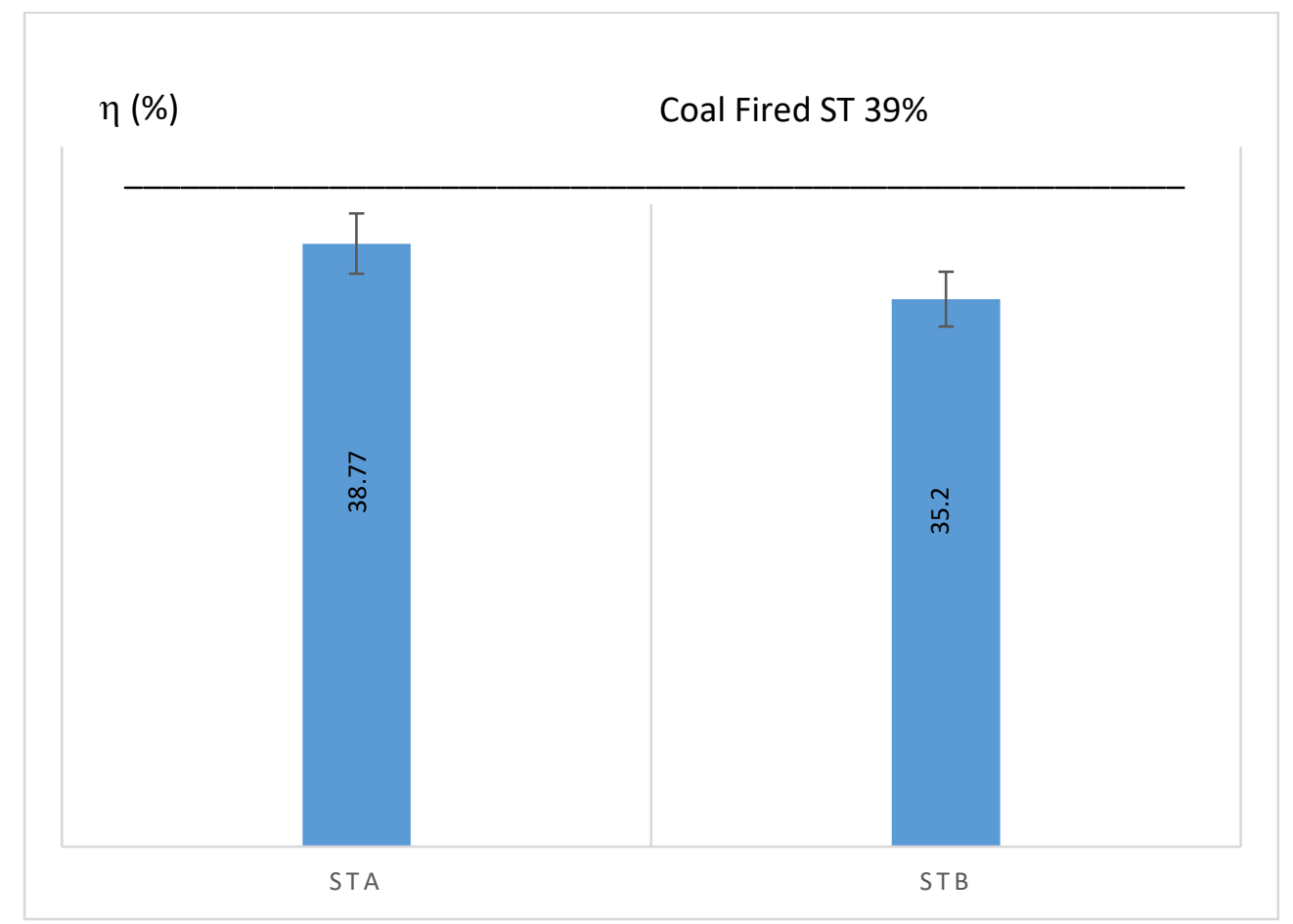

Fig. 1. Energy Conversion Efficiency for Coal Power Plant

Figure 2 shows the energy conversion efficiency for natural gas power plant represented by two units of gas turbines together with overall plant efficiency. The recorded efficiency for the gas turbines; GTA and GTB are at $31.00 \%$ and $30.35 \%$ respectively, while the overall efficiency is at 48.35 $\%$. Both of the gas turbine units are registering lower energy conversion efficiency in comparison with the typical conversion efficiency proposed by EURELECTRIC [20] which are at $39 \%$. The low energy conversion efficiency recorded by both, GTA and GTB can be associated with the ageing effect given that the system was commissioned at 2005 (10 years). However, with the help from the steam turbine, the overall energy conversion efficiency of the plant has been recorded to be at $48.35 \%$ which is relatively closer to the recommended typical value of $58.00 \%$ [20]. In comparison with the coal power plant which the steam turbine units were supplied with steam generated by its boiler, the steam turbine in the combined gas turbine power plant is utilizing the excess heat through the heat recovery system (heat exchanger). This allows a much higher overall conversion efficiency for combined cycle gas turbine power plant in comparison to the coal power plant which needs to consider the combustion efficiency of fuel in its overall efficiency evaluation. 


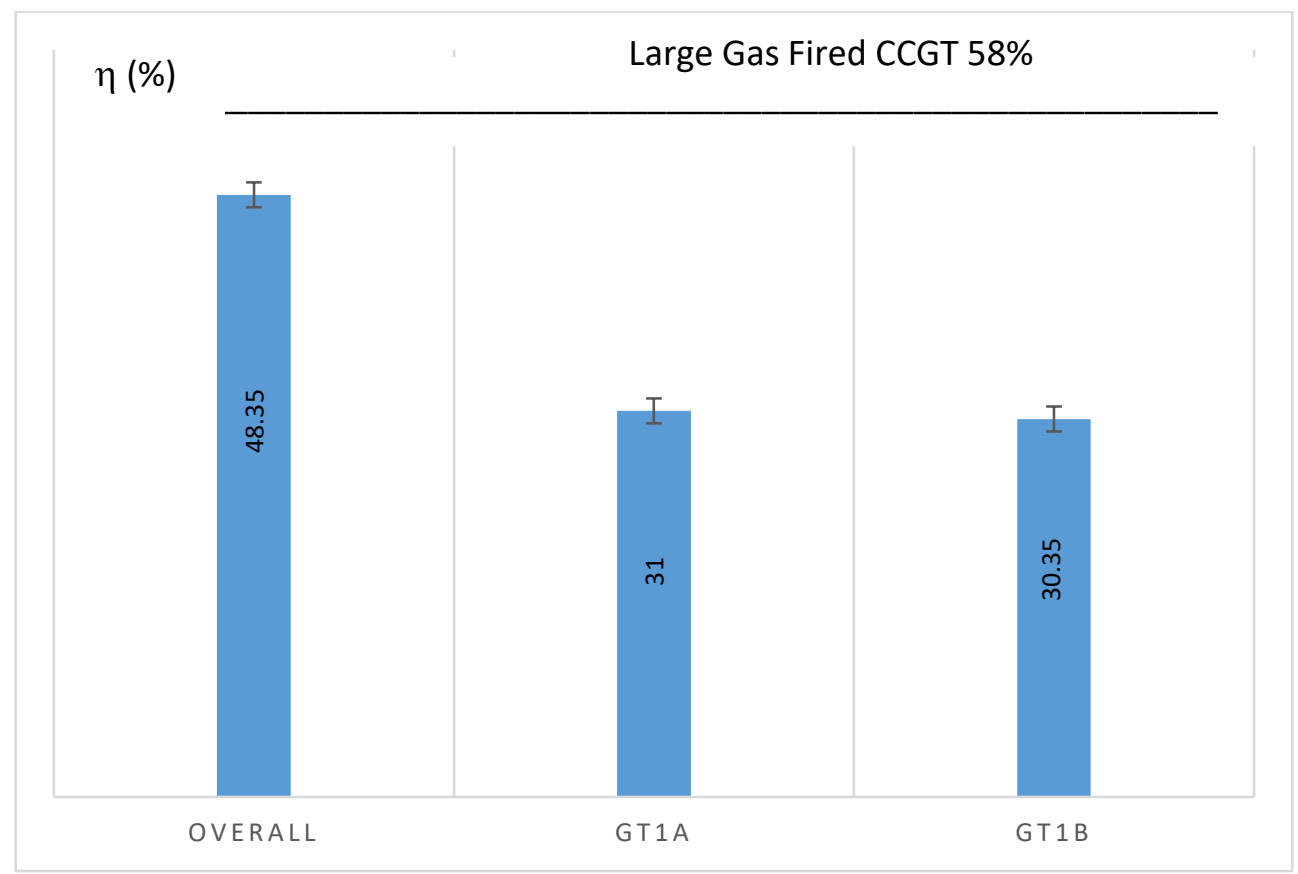

Fig. 2. Energy Conversion Efficiency for Natural Gas Power Plant

Figure 3 shows the recorded energy conversion efficiency for biomass power plant considered in the present study at $6.47 \%$ with $1.91 \%$ standard deviation. The efficiency recorded for the biomass power plant is the lowest in comparison with the other units considered in the present study. The efficiency is also very low in comparison with the recommended value of $22.00 \%$ [20]. The power plant makes use of EFB as their fuel to generate the steam. During the data collection it is observed that the EFB that is supplied to the boiler has not been properly treated; in a chunk and wet. The supplied fuel condition resulting in very low combustion efficiency thus bring down its overall efficiency.

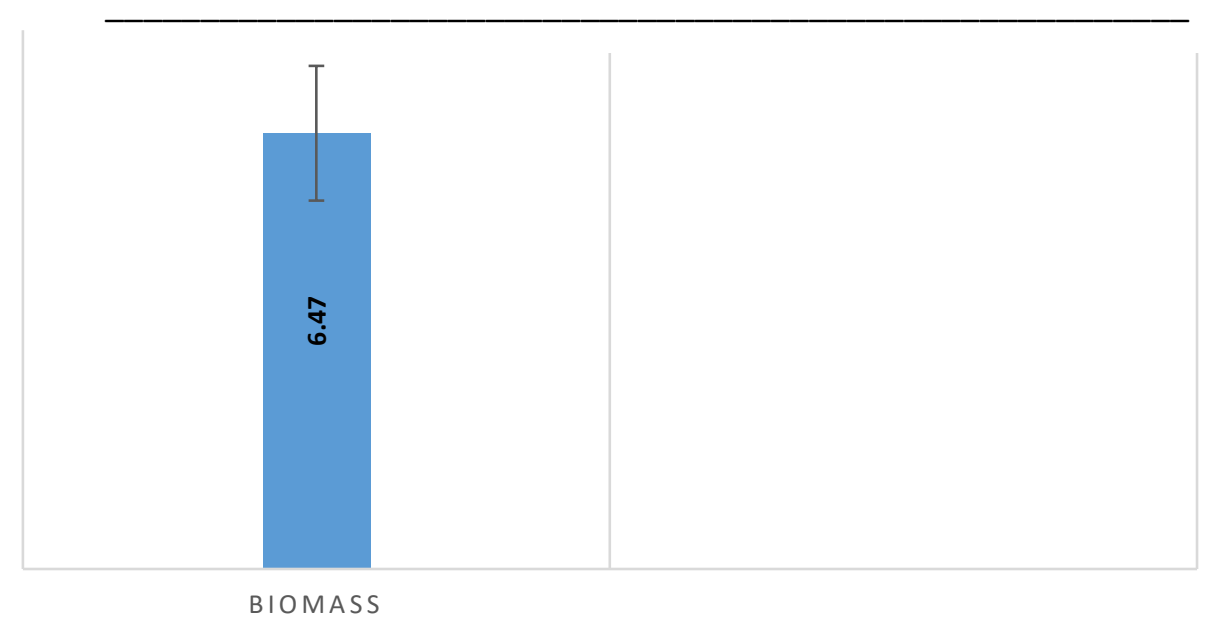

Fig. 3. Energy Conversion Efficiency for Biomass Power Plant 


\subsection{GHG Emission}

To enable comparison between the three different power plants, the GHG emission in a kilogram of carbon dioxide equivalent, $\mathrm{kgCO}_{2} \mathrm{e}$ has been normalized to the generated electricity, $\mathrm{kWh}$ deriving value for a kilogram of carbon dioxide equivalent per unit generated electricity also known as GHG emission rate, $\mathrm{kgCO}_{2}$ e per kWh. Figure 4 shows the recorded GHG emission rate for two units of the steam turbine for the coal power plant. Both of the units (STA and STB) registered GHG emission rate at $0.74 \mathrm{kgCO}_{2} \mathrm{e}$ per $\mathrm{kWh}$ and $0.68 \mathrm{kgCO}_{2} \mathrm{e}$ per $\mathrm{kWh}$ respectively. The values are lower than the proposed value of Steam Cycle Hardcoal of $0.83 \mathrm{kgCO}_{2} \mathrm{e}$ per $\mathrm{kWh}$ [20]. The values reflecting the efficiency values that have been discussed earlier in the previous section, whereby, higher efficiency will register lower emission rate.

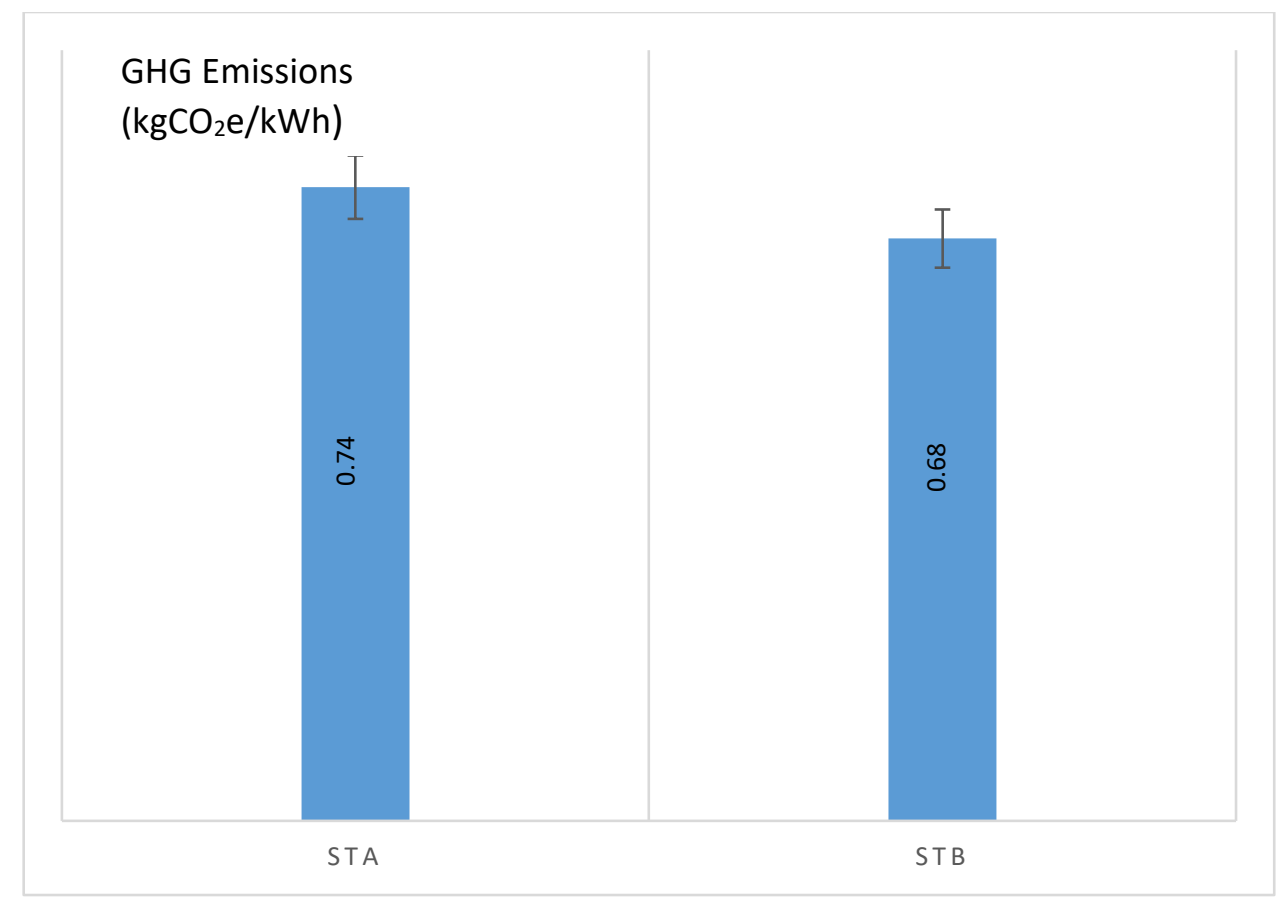

Fig. 4. GHG Emissions Rate for Coal Power Plant

Figure 5 shows the GHG emission rate for the combined cycle gas power plant. The registered values for GTA and GTB are $0.51 \mathrm{kgCO}_{2} \mathrm{e}$ per $\mathrm{kWh}$ and $0.50 \mathrm{kgCO}_{2} \mathrm{e}$ per $\mathrm{kWh}$ respectively. Both of these values are slightly lower than the proposed value at $0.58 \mathrm{kgCO}_{2} \mathrm{e}$ per $\mathrm{kWh}$ of Gas Turbine Cycle [20], despite both of the units are operating at lower efficiency has been discussed earlier in the previous section. It indicates a good opportunity to further reduce the GHG emission rate by improving the unit efficiency. Figure 5 also shows that the overall GHG emission rate for the power is registered to be at $0.32 \mathrm{kgCO}_{2} \mathrm{e}$ per $\mathrm{kWh}$ which is lower than the proposed value at $0.36 \mathrm{kgCO}_{2} \mathrm{e}$ per $\mathrm{kWh}$ of CCGT [20]. The GHG emission rate value for the biomass power plant taken to be at 0 $\mathrm{kgCO}_{2}$ e per $\mathrm{kWh}$ due to the fact that the plant is utilizing EFB as a fuel. The EFB which is produced by the palm tree has been categorized as carbon-neutral fuel; in which the GHG emission from its combustion is said to produce lower $\mathrm{GHG}$ is comparison with the $\mathrm{CO}_{2}$ absorbed by biomass during its growth. 


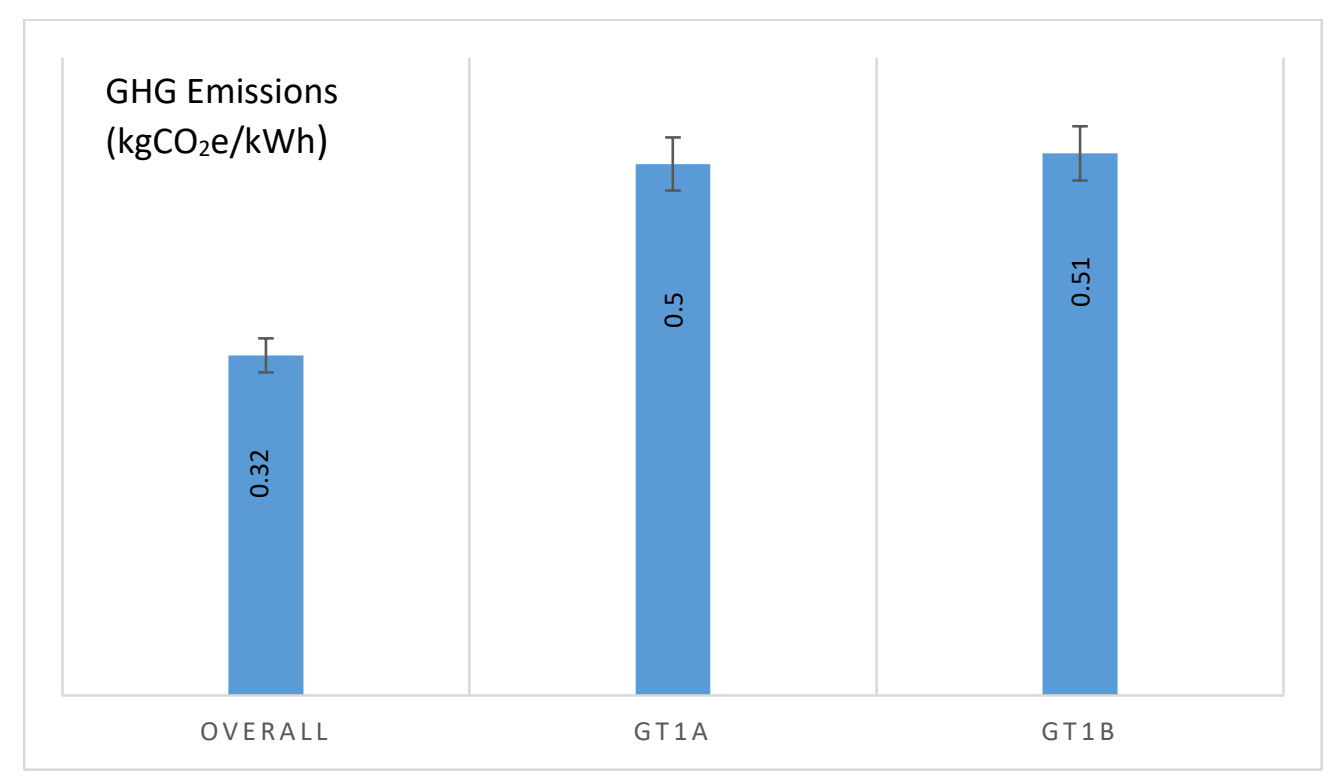

Fig. 5. GHG Emissions Rate for Natural Gas Power Plant

\section{Conclusions}

The study aims to assess and measure the efficiency of different energy conversion systems and its greenhouse gas emissions involving coal power plant, combine cycle natural gas power plant and biomass power plant. Data including fuels consumption and generated electricity for each power plant has been collected to derive two main performance criteria of the present study; energy conversion efficiency, $\eta$ and GHG emission rate. The conclusions for the present study are as follow

i. All considered units in the study are operating at lower energy conversion efficiency in comparison to the recommended typical values.

ii. The overall energy conversion efficiency of the combined cycle power plant is the highest in comparison with the other two power plants due to its capability to utilized excess exhaust heat from the gas turbine system.

iii. The lowest energy conversion efficiency is recorded for the biomass power plant which is contributed by poor fuel handling.

iv. Retrofitting and increasing the efficiency in existing power plants is the current measures in maintaining efficiency.

\section{References}

[1] Zaman, Khalid, Muhammad Mushtaq Khan, and Zohra Saleem. "Bivariate cointegration between energy consumption and development factors: a case study of Pakistan." International Journal of Green Energy 8, no. 8 (2011): 820-833. https://doi.org/10.1080/15435075.2011.602157

[2] Zaman, Khalid, Muhammad Mushtaq Khan, Mehboob Ahmad, and Rabiah Rustam. "The relationship between agricultural technology and energy demand in Pakistan." Energy Policy 44 (2012): $268-279$. https://doi.org/10.1016/i.enpol.2012.01.050

[3] Zaman, Khalid, Muhammad M. Khan, Mehboob Ahmad, and Rabiah Rustam. "Determinants of electricity consumption function in Pakistan: Old wine in a new bottle." Energy Policy 50 (2012): 623-634.. https://doi.org/10.1016/i.enpol.2012.08.003

[4] Zaman, Khalid, Muhammad Mushtaq Khan, Mehboob Ahmad, and Bashir Ahmad Khilji. "RETRACTED: The relationship between agricultural technologies and carbon emissions in Pakistan: Peril and promise." Economic Modelling 29 (2012): 1632-1639. https://doi.org/10.1016/i.econmod.2012.05.024

[5] Giraldo, Jairo, Eduardo Mojica-Nava, and Nicanor Quijano. "Synchronization of isolated microgrids with a communication infrastructure using energy storage systems." International Journal of Electrical Power \& Energy Systems 63 (2014): 71-82. https://doi.org/10.1016/j.ijepes.2014.05.042 
[6] Nur Asyik, Hidayatullah, Stojcevski Blagojce, and Kalam Akhtar. "Analysis of distributed generation systems, smart grid technologies and future motivators influencing change in the electricity sector." Smart Grid and Renewable Energy 2011 (2011). https://doi.org/10.4236/sgre.2011.23025

[7] Vandaele, Nicole, and Wendell Porter. "Renewable energy in developing and developed nations: Outlooks to 2040." Journal of Undergraduate Research 15, no. 3 (2015): 1-7.

[8] National Energy Balance 2016. Suruhanjaya Tenaga, (2018).

[9] Ibrahim, Siti Halipah, Nadia Zaini, Azhaili Baharun, Afzan Ahmad Zaini, Dona Rose Amer Koesmeri, Mohd Nasrun Mohd Nawi, and Faizal Baharum. "Embodied Energy and $\mathrm{CO}_{2}$ Analysis of Industrialised Building System (IBS) and Conventional Building System." Journal of Advanced Research in Fluid Mechanics and Thermal Sciences 51, no. 2 (2018): 259-266.

[10] Balat, Mustafa. "Energy and greenhouse gas emissions: A global perspective." Energy Sources, Part B 1, no. 2 (2006): 157-170. https://doi.org/10.1080/009083190881571

[11] Li, Huanan, Hailin Mu, Ming Zhang, and Shusen Gui. "Analysis of regional difference on impact factors of China's energy-Related $\mathrm{CO}_{2}$ emissions." Energy 39, no. 1 (2012): 319-326. https://doi.org/10.1016/i.energy.2012.01.008

[12] Ghorbani, Afshin, Hamid Reza Rahimpour, Younes Ghasemi, Somayeh Zoughi, and Mohammad Reza Rahimpour. "A review of carbon capture and sequestration in Iran: microalgal biofixation potential in Iran." Renewable and Sustainable Energy Reviews 35 (2014): 73-100. https://doi.org/10.1016/j.rser.2014.03.013

[13] Noorpoor, A. R., and S. Nazari Kudahi. " $\mathrm{CO}_{2}$ emissions from Iran's power sector and analysis of the influencing factors using the stochastic impacts by regression on population, affluence and technology (STIRPAT) model." Carbon Management 6, no. 3-4 (2015): 101-116. https://doi.org/10.1080/17583004.2015.1090317

[14] Lindeburg, Michael R. Mechanical engineering reference manual for the PE exam. www. ppi2pass. com, 2013.

[15] Wiedmann, Thomas, and Jan Minx. "A definition of 'carbon footprint'." Ecological economics research trends 1 (2008): 1-11.

[16] Energy Commission. "Peninsular Malaysia Electricity Supply Outlook 2017." Suruhanjaya Tenaga (Energy Commission) (2017).

[17] MESTECC. "Malaysia Third National Communication and Second Biennial Update Report To The UNFCC." (2018).

[18] Samsudin, M. S. N. B. M. M. S. N. B., Md Mizanur Rahman, and Muhamad Azhari Wahid. "Sustainable power generation pathways in Malaysia: Development of long-range scenarios." Journal of Advanced Research in Applied Mechanics 24, no. 1 (2016): 22-38.

[19] Eggleston, Simon, Leandro Buendia, Kyoko Miwa, Todd Ngara, and Kiyoto Tanabe. "IPCC guidelines for national greenhouse gas inventories." (2006): 2006.

[20] EURELECTRIC Preservation of Resources Working Group (2003), "Efficiency in Electricity Generation". Technical Report by EURELECTRIC "Preservation of Resources" Working Group in collaboration with VGB PowerTech. 